\title{
BMJ Open Which moral barriers and facilitators do physicians encounter in advance care planning conversations about the end of life of persons with dementia? A meta- review of systematic reviews and primary studies
}

Angela JJM Keijzer-van Laarhoven (1) , ${ }^{1,2,3,4}$ Dorothea P Touwen, ${ }^{2}$ Bram Tilburgs, ${ }^{3}$ Madelon van Tilborg-den Boeft, ${ }^{3,5}$ Claudia Pees, ${ }^{6}$ Wilco P Achterberg, ${ }^{3}$ Jenny $T$ van der Steen (iD ${ }^{3}$

To cite: Keijzer-van Laarhoven AJJM, Touwen DP, Tilburgs B, et al. Which moral barriers and facilitators do physicians encounter in advance care planning conversations about the end of life of persons with dementia? A meta-review of systematic reviews and primary studies. BMJ Open 2020;10:e038528. doi:10.1136/ bmjopen-2020-038528

- Prepublication history and additional material for this paper is available online. To view these files, please visit the journal online (http://dx.doi.org/10. 1136/bmjopen-2020-038528).

Received 01 April 2020 Revised 12 September 2020 Accepted 25 September 2020

Check for updates

(C) Author(s) (or their employer(s)) 2020. Re-use permitted under CC BY-NC. No commercial re-use. See rights and permissions. Published by BMJ.

For numbered affiliations see end of article.

\section{Correspondence to} Angela JJM Keijzer-van Laarhoven;

A.J.J.M.Keijzer@lumc.nl and Jenny T van der Steen; jtvandersteen@lumc.nl

\section{ABSTRACT}

Importance and objective Conducting advance care planning (ACP) conversations with people with dementia and their relatives contributes to providing care according to their preferences. In this review, we identify moral considerations which may hinder or facilitate physicians in conducting ACP in dementia.

Design For this meta-review of systematic reviews and primary studies, we searched the PubMed, Web of Science and PsycINF0 databases between 2005 and 30 August 2019. We included empirical studies concerning physicians' moral barriers and facilitators of conversations about end-of-life preferences in dementia care. The protocol was registered at Prospero (CRD42019123308).

Setting and participants Physicians and nurse practitioners providing medical care to people with dementia in long-term and primary care settings. We also include observations from patients or family caregivers witnessing physicians' moral considerations.

Main outcomes Physicians' moral considerations involving ethical dilemmas for ACP. We define moral considerations as the weighing by the professional caregiver of values and norms aimed at providing good care that promotes the fundamental interests of the people involved and which possibly ensues dilemmas.

Results Of 1347 studies, we assessed 22 systematic reviews and 51 primary studies as full texts. We included 11 systematic reviews and 13 primary studies. Themes included: (1) beneficence and non-maleficence; (2) respecting dignity; (3) responsibility and ownership; (4) relationship and (5) courage. Moral dilemmas related to the physician as a professional and as a person. For most themes, there were considerations that either facilitated or hindered ACP, depending on physician's interpretation or the context.

Conclusions Physicians feel a responsibility to provide high-quality end-of-life care to patients with dementia. However, the moral dilemmas this may involve, can lead to avoidant behaviour concerning ACP. If these dilemmas are not recognised, discussed and taken into account,
Strengths and limitations of this study

- This study exclusively focuses on moral barriers and facilitators to advance care planning to increase depth on reasons including moral dilemmas behind possible practical barriers and facilitators while other reviews have studied barriers and facilitators more generally.

- To further increase depth and to minimise chances of missing important barriers and facilitators, the review covered both systematic reviews and primary studies.

- We could not compare study quality in a valid manner as there was no good tool to appraise the quality of the evidence of the moral considerations we $a b-$ stracted while the tools we used may be suboptimal for our purpose.

implementation of ACP as a process between physicians, persons with dementia and their family caregivers may fail.

\section{INTRODUCTION}

Advance care planning (ACP) requires discussing medical, psychological, social, spiritual and existential issues, being aware of patients' norms and values, life events and what really matters to them in the last phase of life. ${ }^{12}$ The patient's perspective may be lost when ACP is not discussed directly with patients themselves, not carried out in advance, or focuses mainly on preferred medical interventions, such as decisions around hospitalisation or withholding lifeprolonging treatment. ${ }^{34}$

Although evidence on effectiveness in dementia is still limited, ACP may be particularly important for patients with dementia. ${ }^{56}$ 
Due to the cognitive decline and progression of the disease, patients with dementia will become less competent to express their values and preferences regarding the end of life (EOL), ${ }^{7}$ and they become dependent on others to arrange their EOL care. ${ }^{13-11}$ This increases the relevance of starting the conversation in the earliest phase of the disease. ${ }^{1213}$

However, patients' interests may change over time, whether due to a change in personality as a result of the disease or not. ${ }^{136814-17}$ Despite physicians' aims to make decisions based on the patient's autonomy ${ }^{18-20}$ and best interests, ${ }^{10} 21$ a reserved and ambivalent attitude to ACP, specifically concerning patients with dementia, ${ }^{22}$ is observed among physicians. Physicians may experience specific ethical dilemmas which may involve moral considerations such as those related to anxiety, hope and relationships ${ }^{23}{ }^{24}$ which previous reviews did not address in depth as they mostly reported organisational and practical barriers. The aim of this meta-review of systematic reviews and primary studies is to better understand these moral considerations that present physicians and nurse practitioners (further referred to as physicians) in longterm care (LTC) and primary care settings with ethical dilemmas regarding ACP with patients with dementia and their family caregivers.

\section{METHODS}

We regard ACP in dementia-due to exclusion of persons with no capacity in general work around $\mathrm{ACP}^{25}$-as a communication process between physicians, patients if possible and family caregivers or other relatives to understand personal preferences for care goals, treatments and other wishes regarding the EOL. We define moral considerations as the weighing by the professional caregiver of values and norms aimed at providing good care that promotes the fundamental interests of the people involved and which possibly ensues dilemmas. ${ }^{26}$

\section{Search strategy}

We systematically searched the PubMed, Web of Science and PsycINFO databases. We combined the search terms:

Table 1 Search strategy and inclusion criteria

\section{Search strategy}

\begin{tabular}{|c|c|c|}
\hline PubMed & Web of science & PsycINFO \\
\hline ("dementia"(mesh] OR neurocognit*(tiab] & ("dementia" OR neurocognit* OR & (DE “Dementia” OR DE “Alzheimer's \\
\hline OR “cognitive”(tiab] OR “cognition”(tiab] & “cognitive” OR “cognition” OR & Disease" OR neurocognit* OR TI \\
\hline OR "dementia"(tiab] OR "dementias"(tiab] & "neurocognitive" OR "Alzheimer" & "dementia*" OR TI "Alzheimer" OR TI \\
\hline OR “Alzheimer"(tiab] OR & OR “amnesia*” OR “amnesic") AND & "cognitive" OR TI "cognition" OR TI \\
\hline “Alzheimer's”(tiab] OR “amnesia”(tiab] & "Advance Care Plan*" & "neurocognitive" OR "amnesia"” OR TI \\
\hline OR “amnesias”(tiab] OR “amnesic”(tiab)) & & "amnesic" OR AB "dementia"” OR AB \\
\hline AND ("Advance Care Planning"(Mesh] OR & & "Alzheimer" OR AB "cognitive" OR AB \\
\hline \multirow[t]{4}{*}{ Advance Care Plan*(tiab)) } & & "cognition" OR AB "neurocognitive" OR \\
\hline & & "amnesia*” OR AB “amnesic") AND (DE \\
\hline & & "Advance Directives" OR TI "Advance \\
\hline & & $\begin{array}{l}\text { Care Plan*” OR AB "Advance Care } \\
\text { Plan*") }\end{array}$ \\
\hline
\end{tabular}

Inclusion and exclusion criteria

\section{Inclusion criteria:}

(1) Reporting on empirical data

(2) A population or an identifiable subgroup diagnosed with dementia

(3) ACP in the context of a long-standing relationship between the physician, the patient with dementia and his/her relatives

(4) Care provided in long-term care (LTC) and primary care settings

(5) Barriers to and facilitators of ACP on the part of the physician and described from various perspectives

(6) Studies emphasising moral considerations as a barrier or facilitator for the physician

\section{Exclusion criteria:}

(1) Studies about consent for research participation

(2) ACP limited to drawing up an advance directive that is not brought to the attention of a physician

(3) Theoretical, legal and ethical issues that are not barriers to or facilitators of ACP for the Physician

(4) Studies that exclusively consider advance decision making on euthanasia

$\mathrm{ACP}$, advance care planning. 
dementia and ACP as MeSH terms, free-text words and equivalent index words (table 1). The search was limited to articles in English, Dutch, French and German and published in peer-reviewed journals between 1 January 2005 and 11 May 2018, and was updated on 30 August 2019. We checked the reference lists of included systematic reviews for additional primary studies and searched for relevant grey literature.

\section{Types of studies}

We included systematic reviews, defined as reviews with a systematic search strategy, and additional primary studies that were not included in the systematic review and that met the criteria listed in table 1 .

\section{Study selection}

We followed the Preferred Reporting Items for Systematic Reviews and Meta-Analyses Statement for Reporting Systematic Reviews and Meta-Analyses of studies that Evaluate Health Care Interventions. ${ }^{27}$ After removing duplicates, using Endnote X9 software, four researchers (AK-vL, MvT-dB, BT and JvdS) independently screened all remaining studies for possible eligibility by reading titles and abstracts. Disagreements were discussed in this team. The full text of studies that met the inclusion criteria was independently read and assessed for eligibility in pairs (AK-vL, MvT-dB, BT or DT). Disagreements were resolved through discussions with a third researcher (JvdS). For the process of data extraction, we refer to the Prospero protocol. (online supplemental file 1)

\section{Thematic analysis}

The included studies were analysed using qualitative analysis software ATLAS.ti V.7. Through inductive coding, ${ }^{28} 80 \%$ of these studies were independently coded by two researchers (DT, AK-vL). The codes were repeatedly compared and discussed to reach agreement. In the event of disagreement on the relevance of a code, the team discussed until consensus was reached and a set of codes was established. One researcher (AK-vL) subsequently coded the remaining $20 \%$. Codes with similar content were merged while differentiating facilitators and barriers. Related groups of codes were subsequently combined into categories. Finally, we merged the categories into themes describing the main moral considerations.

\section{Methodological quality}

The methodological quality of the primary studies was determined independently by two researchers (BT, AK-vL) using the Mixed-Methods Appraisal Tool (MMAT) range 0 (no quality criterion met) to 100 (all five criteria met)). The systematic reviews-except for scoping reviews ${ }^{29}$ were appraised independently by AK and HS using AMSTAR-2 (A MeaSurement Tool to Assess systematic Reviews) with no scoring as recommended for AMSTAR-2. ${ }^{30}$

\section{RESULTS}

The search resulted in 11 systematic

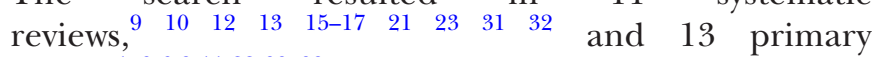

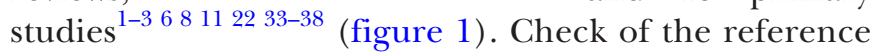
lists of the systematic reviews did not yield any relevant additional primary studies.

The 11 systematic reviews included qualitative or mixedmethods studies; none included quantitative studies only. Three were scoping reviews with systematic searches (table 2). Of the 13 primary articles, nine reported on qualitative research, two reported on quantitative research and two had a mixed-methods design (table 3). Most of the primary studies (9) were conducted in the UK, and settings varied (home, hospital, nursing home).

\section{Methodological quality}

MMAT ratings for primary studies varied between 20 and 100 (see online supplemental table 1). The overall quality of five studies rated 80 or 100 , six studies achieved ratings of 60 , and two studies rated 40 or less. The quality of the eight assessed systematic reviews was rated critically low.

The thematic analysis identified five themes: (1) beneficence and non-maleficence; (2) respecting dignity; (3) responsibility and ownership; (4) relationship and (5) courage (table 4 ).

\section{Beneficence and non-maleficence}

Physicians generally aim to provide care according the principles of beneficence and non-maleficence, and therefore, intend to act in patient's best interest from their own professional perspective and that of others including patients and family caregivers. In practice this intention facilitates ACP, promoting awareness of the patient's previous wishes. However, it can also create barriers and hence, dilemmas for conducting ACP.

Category: providing good care and decision making at the EOL Physicians aim to provide good care in the interest of the patient, particularly at the EOL, ${ }^{1021}$ and avoid unnecessary suffering. ${ }^{1} 153334$ Being aware of the patient's previous wishes helps physicians to resolve possible disagreement between patients and family caregivers and to avoid crises in decision making. ${ }^{16}{ }^{23}$ However, a dilemma emerges when he fears that discussing a patient's interest uncovers conflicting views, ${ }^{269162235}$ or when discussing the implementation of earlier wishes is not in the actual best interest of the patient. ${ }^{2} 689162235$ Another dilemma arises when the physician notices a shift in the patient's response in time, signifying that patient's preferences deviate from anticipatory beliefs. ${ }^{6}$

Physicians also aim to avoid adding emotional burden to the patient, ${ }^{138921313335}$ and provide emotional support to family caregivers. ${ }^{2-10} 1234$ These intentions will on the one hand motivate starting and conducting ACP conversations. ${ }^{2} 69101234$ On the other hand, fear of inducing anxiety or emotional harm may induce reluctance to start conversations about the EOL. 


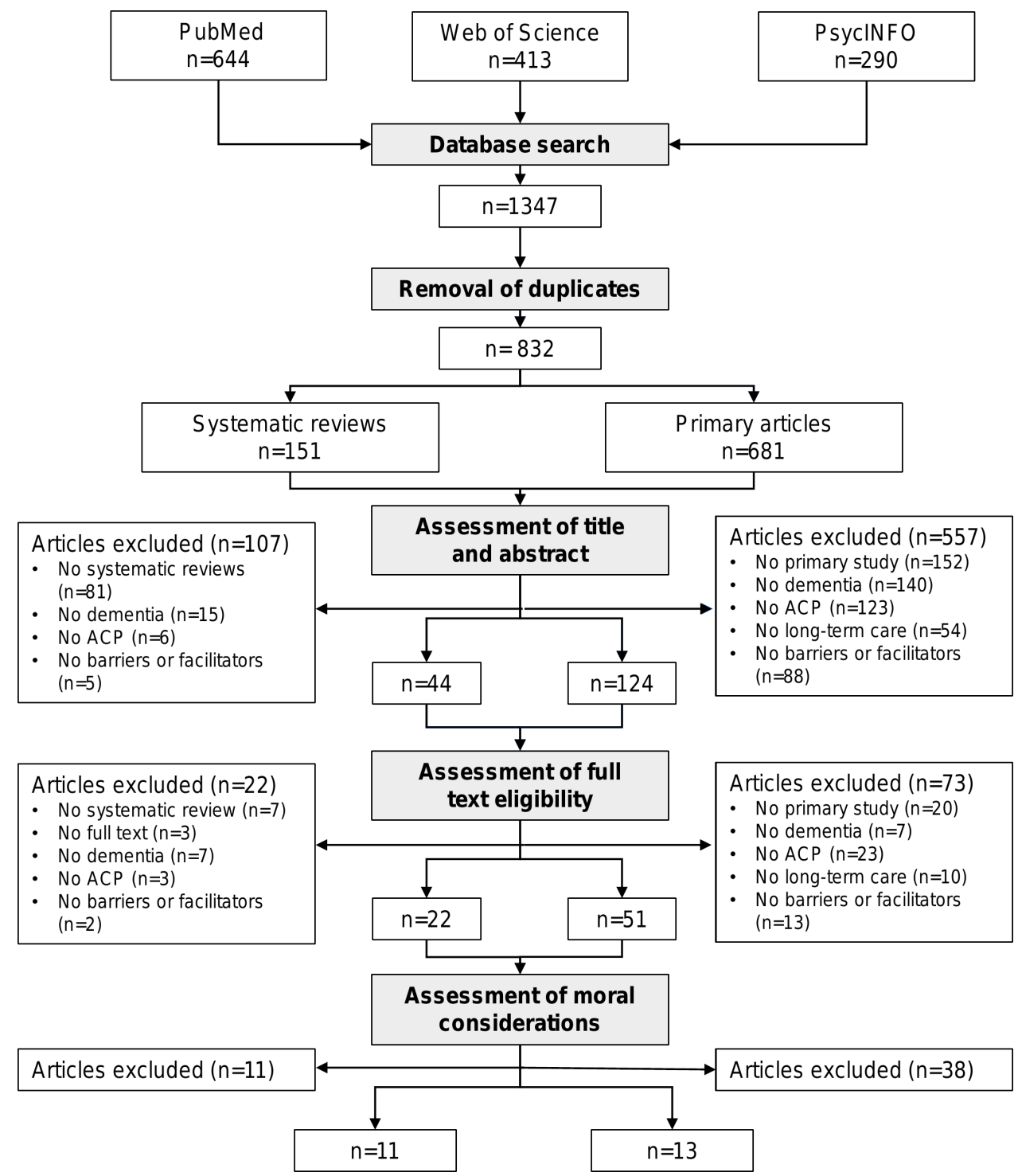

Figure 1 Preferred Reporting Items for Systematic Reviews and Meta-Analyses flow diagram. ACP, advancecare planning.

\section{Category: maintaining hope for the future}

De Vleminck $e t a l^{3}$ and Lai $e t a l^{21}$ note that physicians in general aim to provide and maintain the patient's hope for the future, but fear that discussing the diagnosis and prognosis of dementia can take away hope. ${ }^{289} 3133$ This dilemma arises because physicians are aware of the uncertainties in prognoses and a future that can only be captured in hypothetical scenarios. ${ }^{11} 13161736$ This may result in reluctance to make advance decisions. ${ }^{1316} \mathrm{~A}$ fear to induce anxiety by discussing the future can make the physician even more hesitant. ${ }^{3893}$

Additionally, physicians observe that patients with dementia themselves often prefer not to initiate such discussions about future care, because they are unaware of the diagnosis and prognosis or because of diminished decision-making capacity. ${ }^{3} 1333$ A preference of people with dementia to focus on immediate rather than on

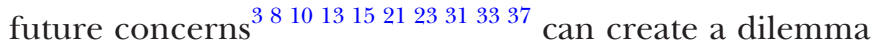
when deemed at odds with the intention to provide hope for the future.
Categories: physician's professional and personal attitude towards talking about death and dying

Despite findings that physicians who have more professional experience witnessing patients' illness or death are more motivated to conduct ACP, ${ }^{23}$ many authors report that physicians feel uncomfortable discussing death or the approaching EOL with their patients. ${ }^{38101721233435}$ This hesitation is reinforced by the patient or the family caregiver either actively or passively avoiding discussing dying. ${ }^{1-38} 10111317222333-35$

Patients may show active reluctance to face the EOL, ${ }^{23}$ and avoid all conversations about their own death. ${ }^{8}$ Passive avoidance of the conversation is observed when the patient puts all his faith in the physician, ${ }^{23}$ or postpones talking about the future. ${ }^{17}$ In addition, family caregivers may not want to discuss their relative's preferences because they do not want to think about, or accept their relative's EOL. ${ }^{2} 101123$

Booij et at emphasise that besides being a professional, the physician is also a 'fellow human being,' who may 


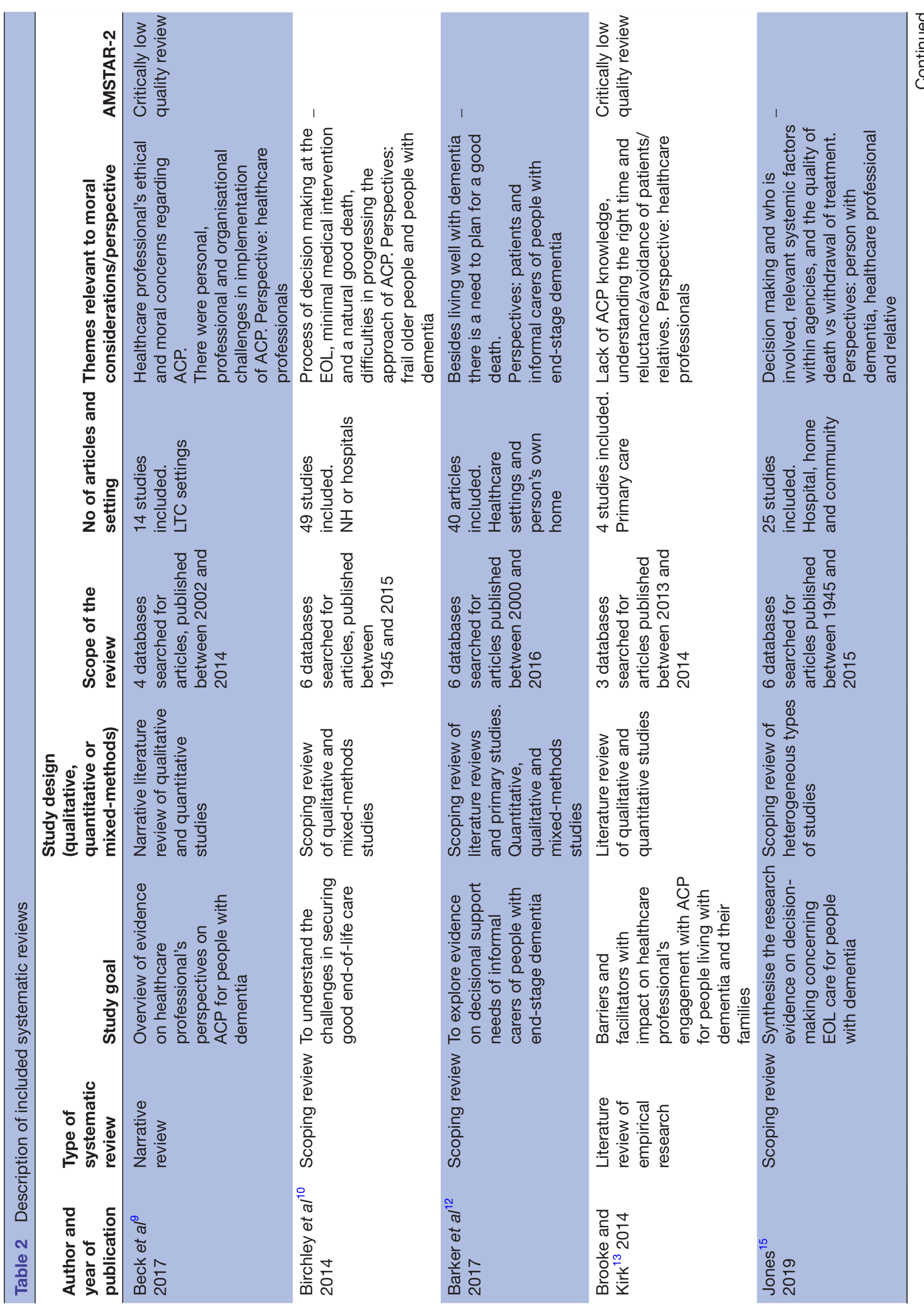




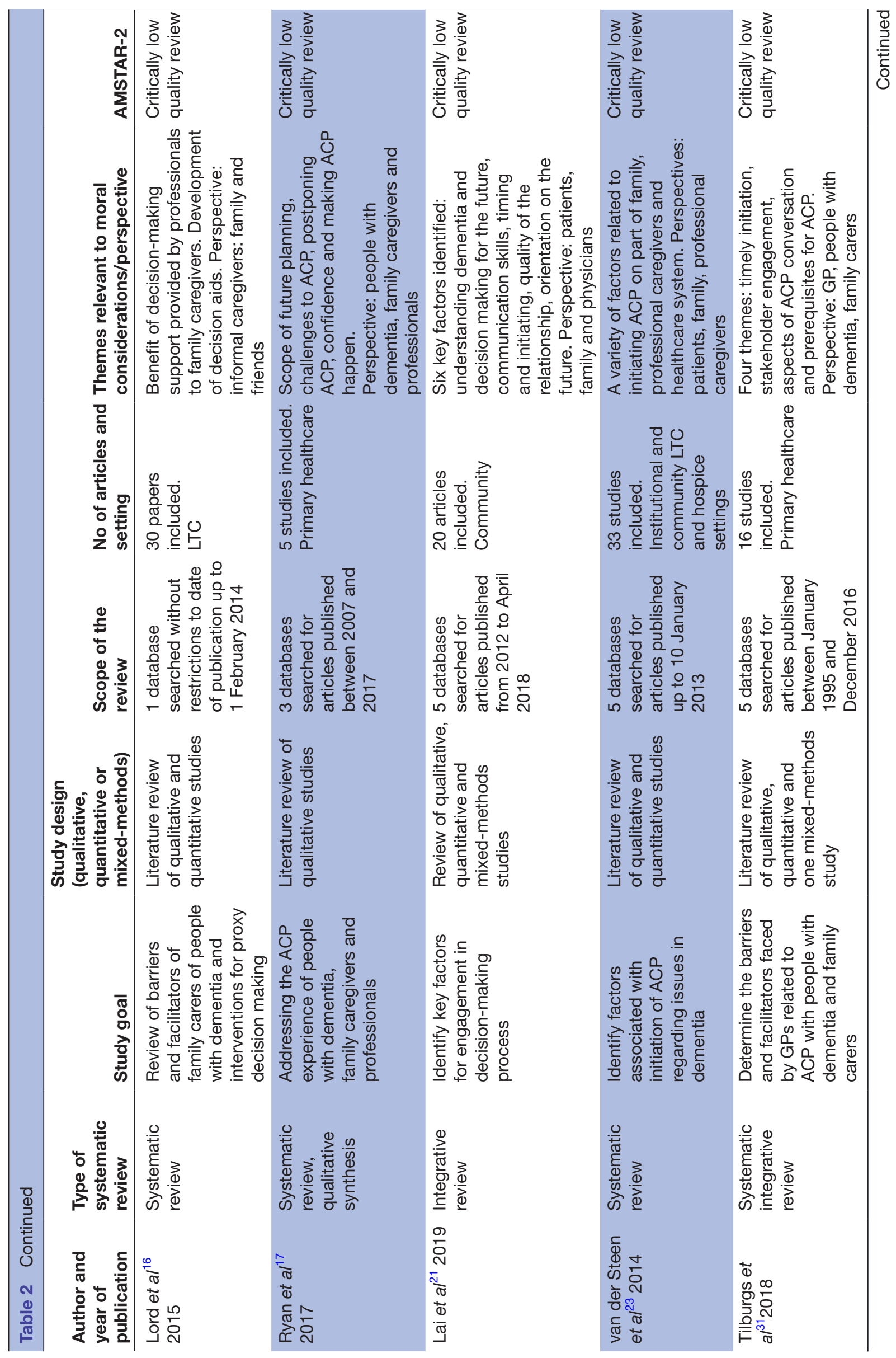


experience a conflict of interests. Physicians' personal experiences with death can result in a moral conflict between the required professional role and private feelings. ${ }^{9} 101335$ Physicians who are motivated to follow the professional standards based on established guidelines can experience a dilemma when they feel that in a specific, individual case, following these guidelines is harmful. ${ }^{23} 35$

\section{Respecting dignity}

Category: good death

Maintaining or improving quality of life at the EOL is often reported as an important goal for physicians to pursue. This involves a good death, dying with dignity, ${ }^{9} 1635$ and a process in accordance with a person's wishes and ethical standards. ${ }^{3}$ However, being confronted with different views on what a good death means, reduces physicians' willingness to initiate ACP. ${ }^{1910}$ For example, physicians in favour of more active treatment show a more reserved attitude towards ACP. ${ }^{87}$

Family caregivers regard communication with and coordination of care by physicians in agreement with relatives as important conditions to achieve an EOL free from distress and suffering. ${ }^{13815-1721333436}$ The planning of care and EOL choices, ${ }^{168101122}$ for instance, concerning the place to die, ${ }^{19}$ are seen as important aspects of a good death.

When a physician aims to increase the patient's and family caregiver's control over the EOL, he is more likely to initiate ACP. ${ }^{13}$ An intention to ensure that patients with dementia have the same opportunities as anyone else, ${ }^{1}$ also facilitates ACP. In practice, however, physicians report a gap between family caregivers' expectations concerning the dying process and reality, which creates dilemmas especially when decisions agreed on with the patient are reassessed. ${ }^{10}$

Category: respecting cultural, spiritual and religious beliefs

Physicians who feel a responsibility to respect a patient's life story, religious beliefs, socio-cultural norms and personal values are motivated for ACP. ${ }^{18911} 1633-35$ On the other hand, many authors also report that physicians' personal beliefs, especially when they differ from the patient's or relative's view, adversely affect the motivation for ACP and subsequent EOL decision making. ${ }^{8} 9152335$

Although concordance of values and beliefs facilitates decision making, ${ }^{23}$ physicians with explicit personal beliefs report less perceived control in relation to ACP. ${ }^{83}$ Differences in beliefs or ethnicity between physicians, patients or their families can act as a barrier to ACP for the physician. ${ }^{89151634}$ This applies even more when such differences are observed between the physician and the nursing home's policy. ${ }^{23}$

\section{Category: respecting autonomy, wishes and preferences}

Physicians who aim to maintain the patient's independence as long as possible, and those who promote selfdetermination and a person-centred approach, ${ }^{11721333436}$ regard ACP as a way of maintaining a person's individual 


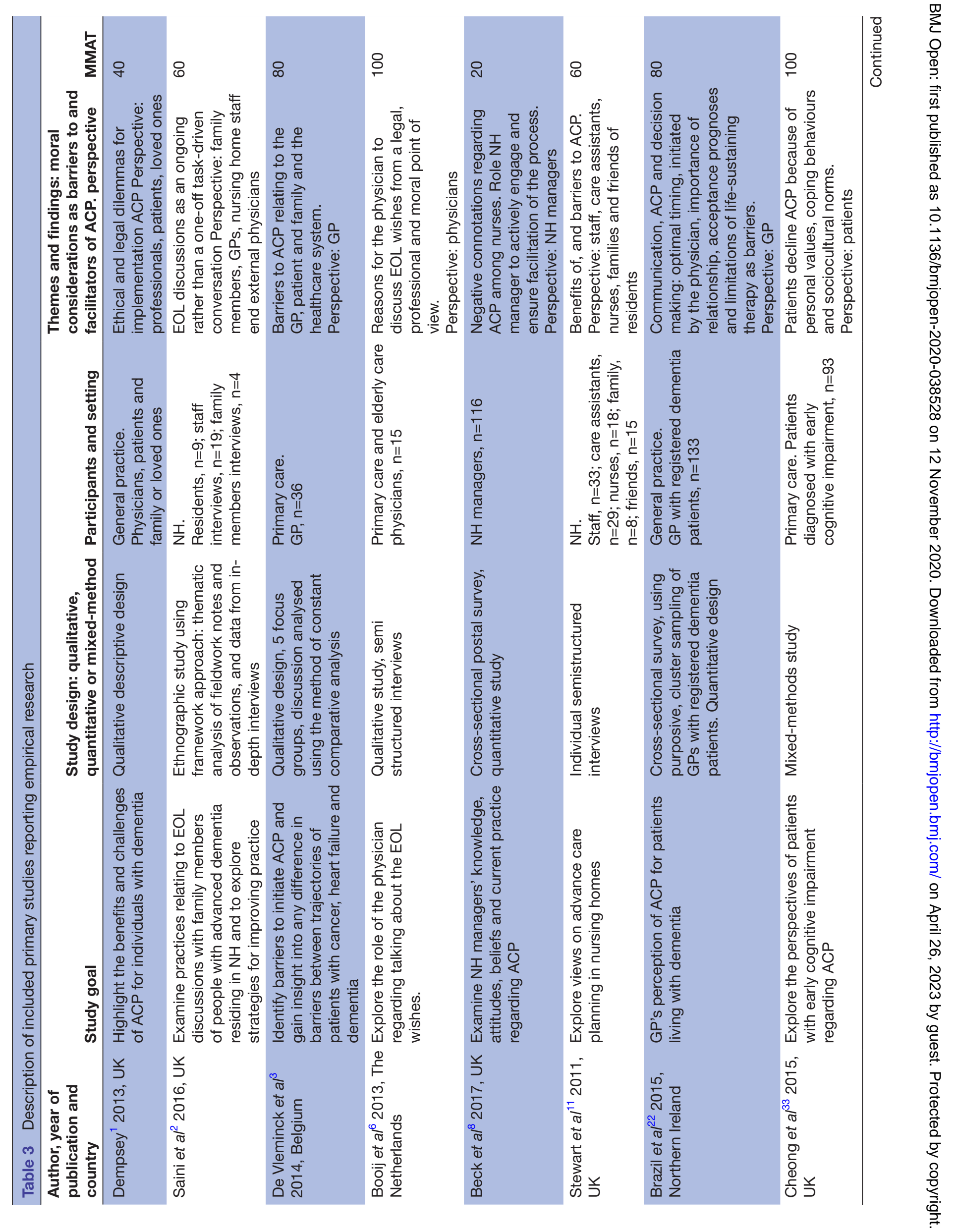




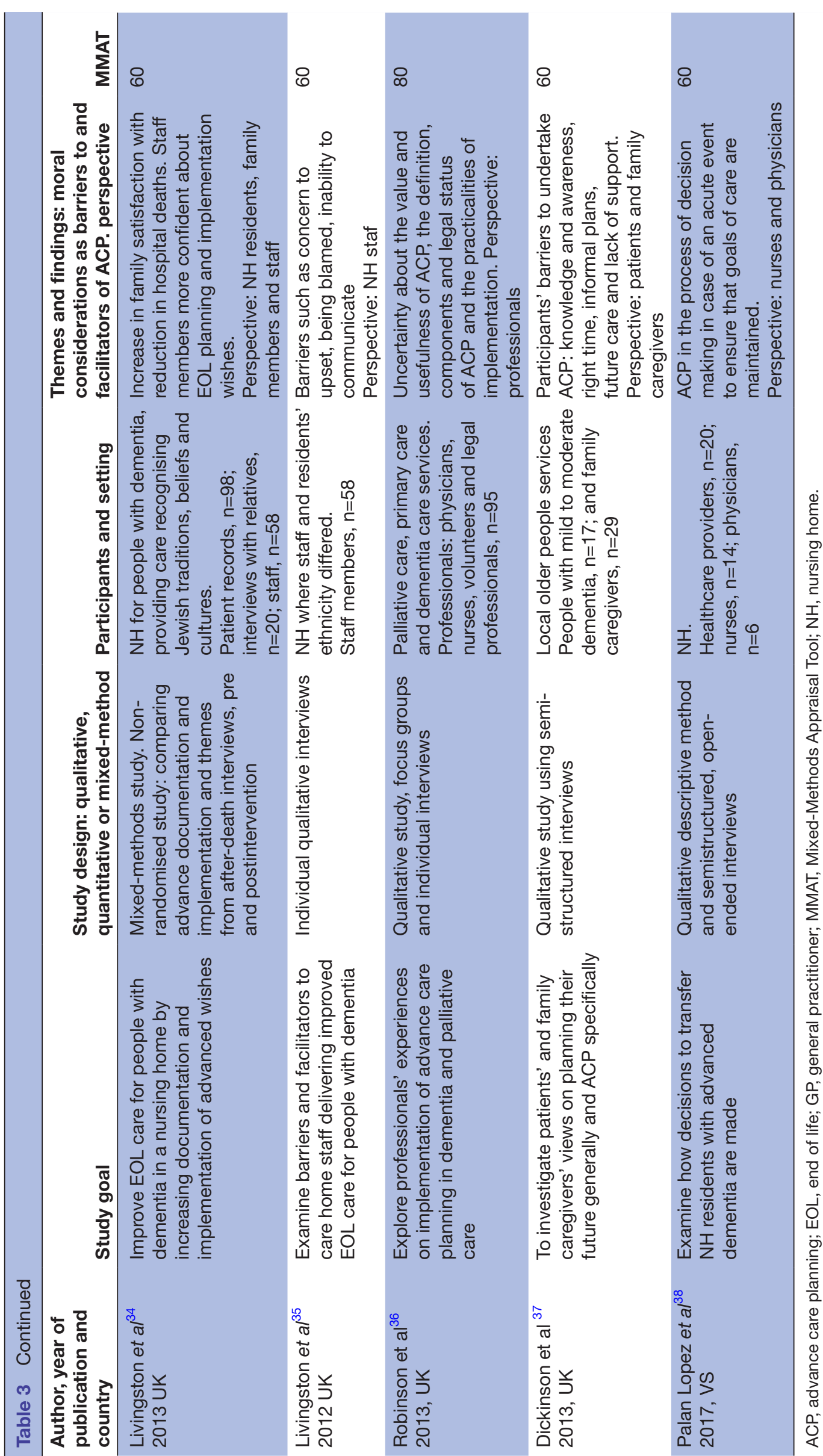




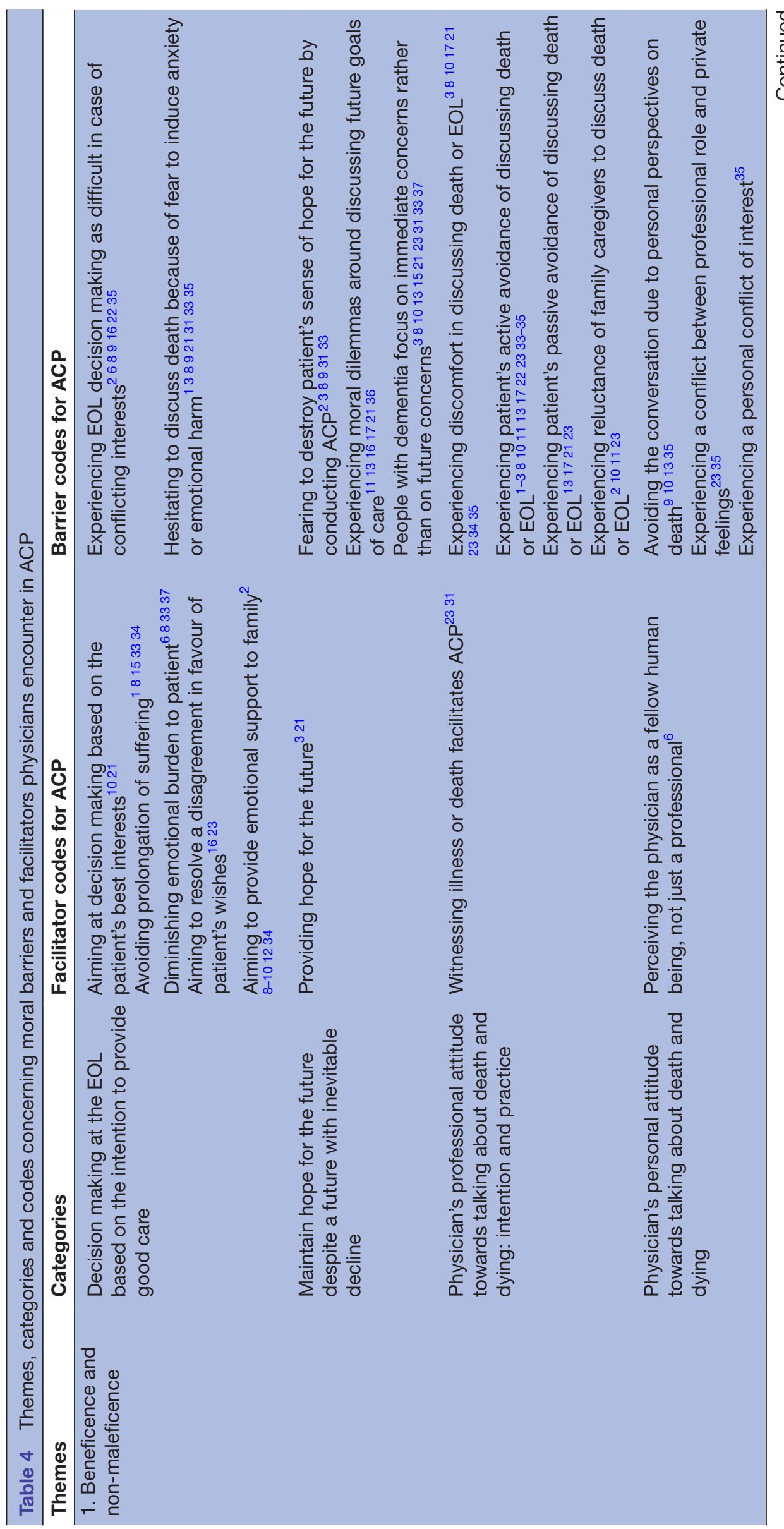




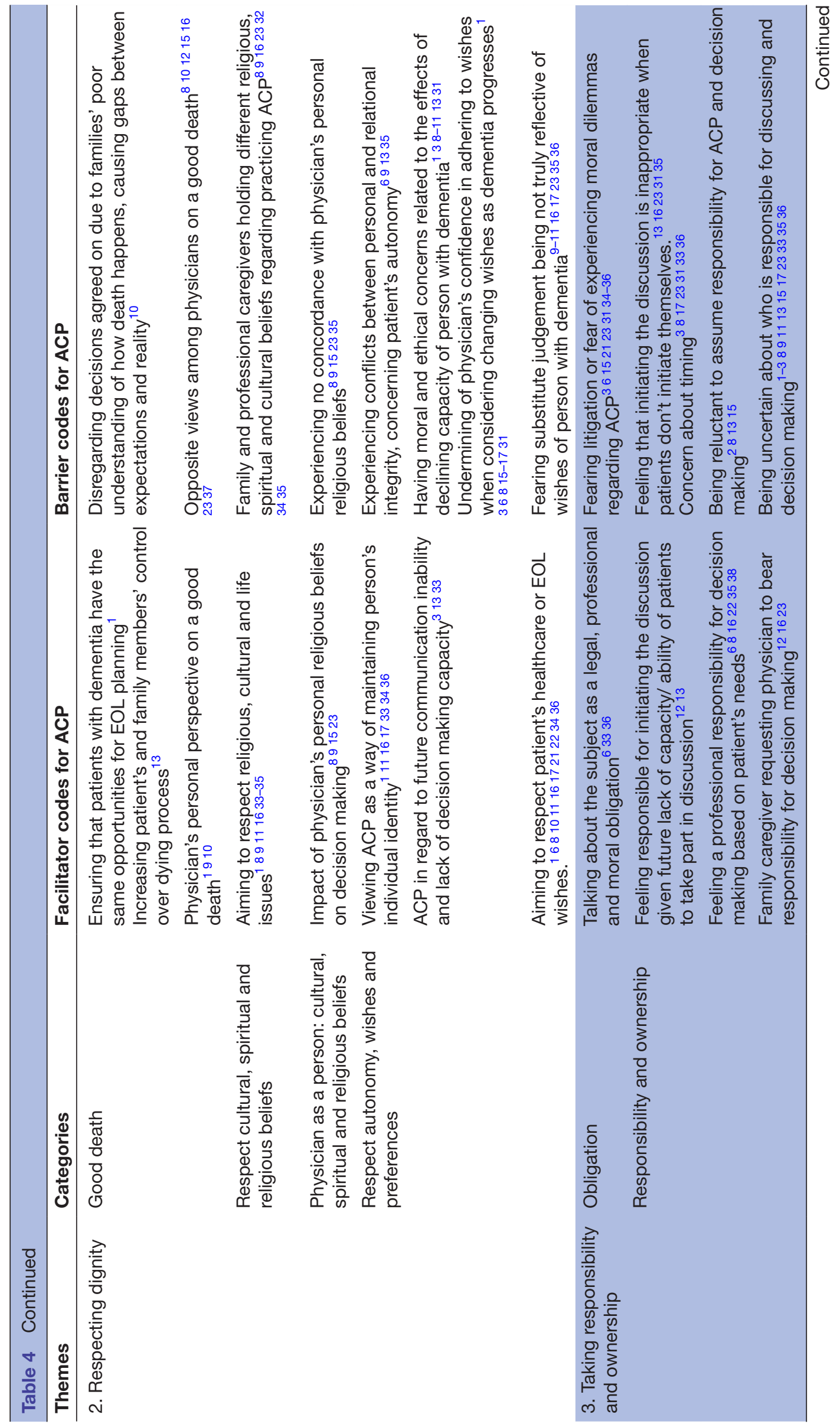




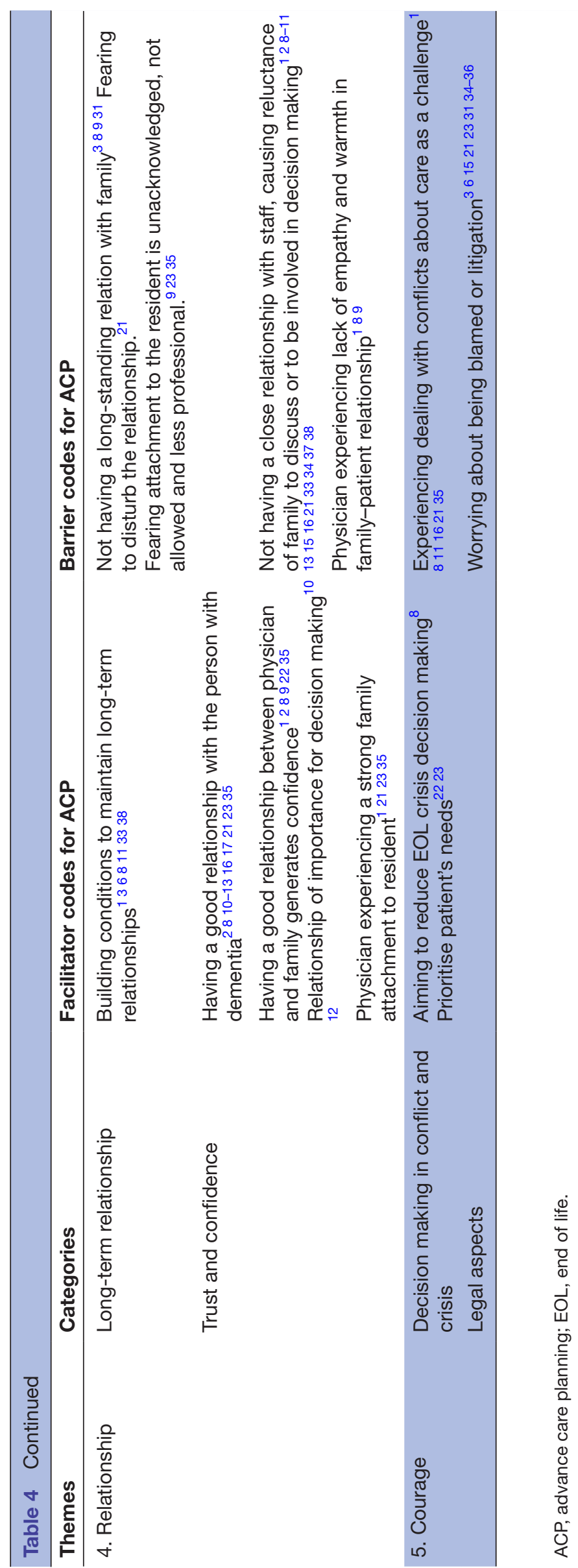

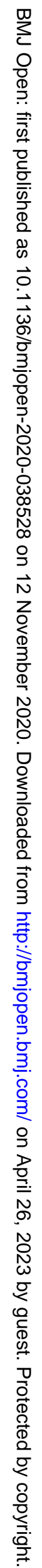


identity. ${ }^{1} 11161721333436$ Honouring the patient's life story, ${ }^{16}$ and respecting the patient's healthcare or EOL wishes, 16810111617223436 is important to physicians who prefer individual decision making based on an existential view rather than collective decision making based on a communitarian view. ${ }^{16}$ Because of future inability to communicate and lack of decision-making capacity in case of dementia, these physicians strongly prefer to conduct ACP.

However, physicians' personal integrity can conflict with their intention to respect the patient's autonomy, ${ }^{6913} 35$ especially when the aim to preserve life contradicts the patient's or family caregiver's wishes, ${ }^{8}$ or when the fulfilment of the expressed wishes seems contrary to the patient's actual best interests. ${ }^{8}$

Lack of awareness of the diagnosis or prognosis impedes patients in making their own choices or even to be engaged in the conversation. ${ }^{3} 1333$ Preferences can change as time passes, which may cause difficulties specifically in the case of cognitive decline. ${ }^{136815-1731}$ The patient will no longer be able to communicate new preferences, and changing one's mind can indicate loss of control, loss of self or loss of identity. ${ }^{189}$ A perceived loss of personality enhances dilemmas for physicians, ${ }^{136815-17}$ for example, when confronted with the decision to either respect current wishes or to regard the patient's prior advance decisions. When the physician has doubts whether the relatives' view may truly be viewed as substituted judgement and adequately reflects the wishes of the patient, ${ }^{9-11} 1617233536$ his dilemma becomes even more obvious.

\section{Taking responsibility and ownership}

\section{Category: obligation}

Physicians view talking about the EOL as a professional and moral obligation. ${ }^{63} 36$ Subsequent agreement on future treatment is considered as a promise not to let the patient down. ${ }^{36}$ Such an obligation can serve as a facilitator for ACP but also as a barrier.

\section{Category: responsibility and ownership}

The responsibility for initiating and conducting $\mathrm{ACP}^{12} 13$ derives from the urgency of reaching decisions in line with the patient's needs or in accordance with his wishes ${ }^{6816223538}$ or at the request of the family caregiver as a substitute decision-maker. ${ }^{12} 1623$ Some studies show that physicians do not want to make decisions in advance at all, but prefer letting others serve as surrogate decision makers. They view ACP and decision making as the others' responsibility. ${ }^{11} 233336$

The prognostic uncertainty in dementia increases physicians' concerns about the right timing. ${ }^{8172333}$ Especially when patients do not initiate the conversation themselves, physicians may regard taking the initiative as inappropriate. ${ }^{1316}$ This uncertainty about who should start the discussion can make physicians reluctant to assume responsibility. ${ }^{1-38131517233536}$

\section{Relationship}

Category: long-term relationship

Long-term relationships facilitate ACP through better understanding of patients' needs, preferences and fears, and of family dynamics. ${ }^{1-3893538}$ However, personal integrity can be at stake when there is doubt about the appropriateness of a physician's personal relationship with the patient, especially if this attachment is considered less professional and therefore impedes ACP. ${ }^{9} 23$ Other considerations include fear to disturb the relationship.

\section{Category: trust and confidence}

Both long-standing relationships and a professional relationship that is characterised by continuity, intensity and trust among all involved, ${ }^{2} 11-1316172335$ can lead to acceptance, understanding and sincerity. ${ }^{1}$ Such experiences make physicians confident regarding ACP. ${ }^{12892235}$ In the context of this relationship it is possible to share values and beliefs, which is important for a desirable level of trust. ${ }^{12}{ }^{23}$ When the physician-family relationship lacks trust, $^{13} 1538$ physicians note passive avoidance or even reluctance on the side of the family to be involved in ACP. ${ }^{101116}$ This may also appear when there are different views between family caregiver and nursing staff.

Additionally, a strong family attachment, 212335 and an involved family caregiver who encourages the patient, facilitate physicians, whereas a family-patient relationship lacking empathy and warmth serves as a barrier for physicians to take the initiative. ${ }^{1892335}$

\section{Courage}

\section{Category: decision making in conflict and crisis}

According to Beck et $a l^{8}$, physicians refuse EOL decision making in a challenging relational crisis, whereas a medical crisis can even trigger tailored decision making. ${ }^{23}$ When a family caregiver's view appears to conflict with the patient's own wishes, whether previously expressed or currently experienced, physicians perceive this as a serious barrier to ACP and hesitate to make decisions at the EOL. ${ }^{1811162135}$

\section{Category: legal aspects}

Physicians express uncertainty about the legal status of ACP, ${ }^{15}$ and may experience a conflict of duties. ${ }^{36}$ They may be worried about being blamed or fear litigation or being viewed as less professional. ${ }^{3} 615212331$ 34-36 They may even fear being held legally accountable if the patient dies, ${ }^{2} 815$ especially when patients change their mind, ${ }^{15} 34{ }^{36}$ or when the family caregiver has different views about care.

\section{DISCUSSION}

This meta-review is unique in its focus on physician's moral considerations in ACP in dementia. We conclude that despite different stages of dementia and (cultural) context, physicians involved in providing medical care within the scope of a long-term relationship, generally 
face the same dilemmas. Several moral considerations can either facilitate or hinder ACP, depending on the physician's personal interpretation or the context in which care is provided. This concerns, for instance, providing hope and comfort. ACP offers an opportunity to provide reassurance, but it could also take away hope for the future and induce anxiety. Also, professional experience with talking about death and providing care to patients with dementia at the EOL can facilitate ACP, while the same experience in private can make physicians hesitant. The same applies to the obligation to act according to patient's expressed wishes, which can function both as a facilitator and a barrier.

This review shows that physicians acknowledge their responsibility for decision making based on patients' autonomy and best interests. Therefore, a moral dilemma arises when striving to preserve patients' identity and autonomy is seen as contrary to the provision of care based on their actual best interests, especially when an observed change of patient's mind does not appear to be the result of a conscious revision of prior wishes. This may result in avoiding ACP in future cases. This main dilemma for physicians is evident from the perspective of physicians themselves, and is also witnessed by others including family caregivers.

Gillett $^{39}$ refers to two possible interpretations of autonomy: the evidentiary view and the integrity view, presented by Dworkin ${ }^{19}$. The evidentiary view states that autonomy means allowing competent patients to decide in their own best interests, as viewed at the moment. In Gillett's view, contemporary wishes should be respected, even if they conflict with a prior ACP and despite cognitive decline and the possibility of anosognosia, to safeguard the patient's sense of freedom. In contrast, in the integrity or existential view of autonomy, the patient's prior advance decision, formulated in the competent phase of their life, is leading. This leaves the physician with a dilemma regarding which course of action to take: to follow the prior wishes outlined in the context of ACP or to honour the patient's apparent wishes now, despite cognitive decline and change of personality and loss of self. Schenell $e t a t^{40}$ promote patients' self-determination by proposing a person-centred approach or, as defined by Wilson and Davies ${ }^{41}$, a relational model of autonomy. Understanding patients' life stories by conducting ACP allows for perceiving people with dementia as the person they were, as well as the person they are now. This will reduce a focus on patient's dependency and strengthen their selves. Making patients and relatives aware of this dilemma and discussing a possible effect of changing wishes on decision making, allows for sharing the responsibility with the patient.

Physicians have a professional responsibility to provide care in accordance with professional standards and norms, based on their patients' best interests and respect for their autonomy while also considering decision-making capacity. Talking about the EOL, as intended by ACP, is regarded as a legal, professional and moral obligation.
However, apart from professional norms, physicians also have their own, potentially conflicting, personal norms, values and feelings. The theory of planned behaviour $\left(\right.$ Ajzen $\left.^{42}\right)$ may apply, describing behaviour predicted by perceived control over the behaviour, and intention. Physicians show a positive attitude and intention towards ACP. However, they encounter several barriers based on professional and personal moral considerations, which cause a serious impediment to physicians' practice of ACP. Despite positive attitudes and intentions, this may explain why physicians may be reluctant with regard to engaging in ACP in practice.

A third important complication relates to physician's doubts whether the relative who acts as a surrogate decision maker truly represents the patient's perspective, or even has the intentions to serve the patient's interests. The fear of being held legally accountable may discourage the physician to show leadership in ACP.

\section{Strengths and limitations}

To increase depth and to decrease the risk of missing important ethical dilemmas and moral considerations that constitute barriers and facilitators to ACP, we analysed both systematic reviews and primary studies. Most studies reported research limited to western societies, but pointed out an influence of different cultural backgrounds and religious and spiritual beliefs on ACP. Nevertheless, they show that the observed dilemmas are consistent across studies. Additionally, we found that family caregivers' observations of physicians' moral considerations were generally consistent with the physicians' own perspectives.

The quality of the systematic reviews was rated critically low based on AMSTAR-2. However, this tool penalises reviews, for example, for not reporting funding sources while intellectual rather than financial conflicts of interests are probably relevant to our and other such reviews. In psychology, AMSTAR-2 had a profound floor effect, $95 \%$ rating critically low. ${ }^{43}$ The quality of the primary articles in our review, however, was rated moderate to high, while findings were consistent with the systematic reviews supporting an explanation that the tools do not fit the purpose of our review on moral considerations.

\section{Recommendations for practice and research}

Physicians regard timely initiation and a structural follow-up of ACP as beneficial for people with dementia, which indicates that barriers to implementation should be overcome. The fact that physicians, besides feeling obliged to conform to professional norms and standards, also encounter personal dilemmas, needs to be acknowledged by patients, relatives, society and by physicians themselves. Further research may study how conflict of personal norms concerning ACP with professional norms might be resolved.

An open, safe and ho nest discussion of the topic, including the detrimental effect it may have on the physician's job satisfaction in the long term, is needed. This is 
a responsibility for the professional association and the healthcare team. The dilemmas we identified may also be addressed during ACP training. Raising awareness should be part of moral education within the context of a structurally provided peer discussions in practice. If these dilemmas are not recognised, discussed and taken into account, ACP will not be generally implemented. This may not only result in poor quality of care provided to the patient with dementia at the EOL, but may also negatively impact bereavement of relatives.

\section{CONCLUSION}

Physicians feel a responsibility to provide high-quality EOL care to patients with dementia. However, the moral dilemmas they encounter may lead to avoidant behaviour concerning ACP practice. If these dilemmas are recognised, the implementation of ACP and, more importantly, physicians' aim to support an EOL in accordance with patient's wishes, may become successful.

\section{Author affiliations}

${ }^{1}$ Department of Expertise and Treatment, Argos Zorggroep, Schiedam, The Netherlands

${ }^{2}$ Department of Medical Ethics and Health Law (E\&R), Leiden University Medical Center (LUMC), Leiden, The Netherlands

${ }^{3}$ Department of Public Health and Primary Care (PHEG), Leiden University Medical Center (LUMC), Leiden, The Netherlands

${ }^{4}$ Department of Expertise and Treatment, Laurens, Rotterdam, The Netherlands ${ }^{5}$ Quin, Amsterdam, The Netherlands

${ }^{6}$ Walaeus Library, Leiden University Medical Center (LUMC), Leiden, The Netherlands

Acknowledgements We would like to acknowledge M. Houtlosser (MH), PhD, member guidance committee and H.J.A. Smaling (HS), PhD for help appraising of the quality of the systematic reviews.

Contributors AK-vL, JvdS and DT had full access to the data of the study and take responsibility for the integrity of the data and the accuracy on the data analysis. Contribution to the conceptualisation and design: AK-vL, DT, WA and JvdS. Search strategy and study selection: AK-vL, BT, MvT-dB and JvdS. Data analysis and interpretation: all authors. Drafting of the manuscript: AK-vL, BT, DT and JvdS. Writing of the article: AK-vL. Critical revision of the manuscript for important intellectual content: all authors. Obtaining funding: AK-vL. Administrative, technical or material support: CP, BT and JvdS. Study supervision: DT and JvdS. All authors read and approved the final manuscript.

Funding This research was supported by Argos Zorggroep, The Netherlands. Competing interests None declared.

Patient consent for publication Not required.

Provenance and peer review Not commissioned; externally peer reviewed.

Data availability statement All data relevant to the study are included in the article or uploaded as online supplemental information.

Supplemental material This content has been supplied by the author(s). It has not been vetted by BMJ Publishing Group Limited (BMJ) and may not have been peer-reviewed. Any opinions or recommendations discussed are solely those of the author(s) and are not endorsed by BMJ. BMJ disclaims all liability and responsibility arising from any reliance placed on the content. Where the content includes any translated material, BMJ does not warrant the accuracy and reliability of the translations (including but not limited to local regulations, clinical guidelines, terminology, drug names and drug dosages), and is not responsible for any error and/or omissions arising from translation and adaptation or otherwise.

Open access This is an open access article distributed in accordance with the Creative Commons Attribution Non Commercial (CC BY-NC 4.0) license, which permits others to distribute, remix, adapt, build upon this work non-commercially, and license their derivative works on different terms, provided the original work is properly cited, appropriate credit is given, any changes made indicated, and the use is non-commercial. See: http://creativecommons.org/licenses/by-nc/4.0/.

\section{ORCID iDs}

Angela JJM Keijzer-van Laarhoven http://orcid.org/0000-0002-3362-1407

Jenny T van der Steen http://orcid.org/0000-0002-9063-7501

\section{REFERENCES}

1 Dempsey D. Advance care planning for people with dementia: benefits and challenges. Int J Palliat Nurs 2013;19:227-34.

2 Saini G, Sampson EL, Davis S, et al. An ethnographic study of strategies to support discussions with family members on end-oflife care for people with advanced dementia in nursing homes. BMC Palliat Care 2016;15:55.

3 De Vleminck A, Pardon K, Beernaert K, et al. Barriers to advance care planning in cancer, heart failure, and dementia patients: a focus group study on general practitioners' views and experiences. J Palliat Care 2014;30:218.

4 Dixon J, Knapp M. Whose job? the staffing of advance care planning support in twelve international healthcare organizations: a qualitative interview study. BMC Palliat Care 2018;17:78.

5 Brinkman-Stoppelenburg A, Rietjens JAC, van der Heide A. The effects of advance care planning on end-of-life care: a systematic review. Palliat Med 2014;28:1000-25.

6 Booij SJ, Engberts DP, Rödig V, et al. A plea for end-of-life discussions with patients suffering from Huntington's disease: the role of the physician. J Med Ethics 2013;39:621-4.

7 Davies N, Klapwijk MS, van der Steen JT. Palliative care in dementia. In: MacLeod RD, Van den Block L, eds. Textbook of palliative care. Berlin, Germany: Springer, 2018.

8 Beck E-R, Mcllfatrick S, Hasson F, et al. Nursing home manager's knowledge, attitudes and beliefs about advance care planning for people with dementia in long-term care settings: a cross-sectional survey. J Clin Nurs 2017;26:2633-45.

9 Beck E-R, Mcllfatrick S, Hasson F, et al. Health care professionals' perspectives of advance care planning for people with dementia living in long-term care settings: a narrative review of the literature. Dementia 2017;16:486-512.

10 Birchley G, Jones K, Huxtable R, et al. Dying well with reduced agency: a scoping review and thematic synthesis of the decisionmaking process in dementia, traumatic brain injury and frailty. BMC Med Ethics 2016;17:46.

11 Stewart F, Goddard C, Schiff R, et al. Advanced care planning in care homes for older people: a qualitative study of the views of care staff and families. Age Ageing 2011;40:330-5.

12 Barker S, Lynch M, Hopkinson J. Decision making for people living with dementia by their carers at the end of life: a rapid scoping review. Int J Palliat Nurs 2017;23:446-56.

13 Brooke J, Kirk M. Advance care planning for people living with dementia. Br J Community Nurs 2014;19:490-5.

14 de Boer ME, Dröes R-M, Jonker C, et al. Advance directives for euthanasia in dementia: do law-based opportunities lead to more euthanasia? Health Policy 2010;98:256-62.

15 Jones K, Birchley G, Huxtable R, et al. End of life care: a scoping review of experiences of advance care planning for people with dementia. Dementia 2019;18:825-45.

16 Lord K, Livingston G, Cooper C. A systematic review of barriers and facilitators to and interventions for proxy decision-making by family carers of people with dementia. Int Psychogeriatr 2015;27:1301-12.

17 Ryan T, Amen KM, McKeown J. The advance care planning experiences of people with dementia, family caregivers and professionals: a synthesis of the qualitative literature. Ann Palliat Med 2017;6:380-9.

18 Dresser R. Treatment decisions and changing selves. J Med Ethics 2015;41:975-6.

19 Dworkin R. Autonomy and the demented self. Milbank Q 1986;64:4-16.

20 Jaworska A. Respecting the margins of agency: Alzheimer's patients and the capacity to value. Philos Public Aff 1999;28:105-38.

21 Lai M, Jeon Y-H, McKenzie $\mathrm{H}$. The key factors for the engagement of primary stakeholders in decision-making for the future care of people with dementia living in the community: a systematic integrative review. Int Psychogeriatr 2019;31:1731-46.

22 Brazil K, Carter G, Galway K, et al. General practitioners perceptions on advance care planning for patients living with dementia. BMC Palliat Care 2015;14:14.

23 van der Steen JT, van Soest-Poortvliet MC, Hallie-Heierman M, et al. Factors associated with initiation of advance care planning in dementia: a systematic review. J Alzheimers Dis 2014;40:743-57. 
24 Rurup ML, Onwuteaka-Philipsen BD, Pasman HRW, et al. Attitudes of physicians, nurses and relatives towards end-of-life decisions concerning nursing home patients with dementia. Patient Educ Couns 2006;61:372-80.

25 Rietjens JAC, van der Heide A, Onwuteaka-Philipsen BD, et al. A comparison of attitudes towards end-of-life decisions: survey among the Dutch general public and physicians. Soc Sci Med 2005;61:1723-32.

26 Beauchamp TL, Childress JF. Principles of biomedical ethics. 7th ed. New York, Oxford: Oxford University Press, 2013: 20.

27 Liberati A, Altman DG, Tetzlaff J, et al. The PRISMA statement for reporting systematic reviews and meta-analyses of studies that evaluate health care interventions: explanation and elaboration. $J$ Clin Epidemiol 2009;62:e1-34.

28 Whittemore $\mathrm{R}$, Knafl K. The integrative review: updated methodology. J Adv Nurs 2005;52:546-53.

29 Peters MDJ, Godfrey CM, Khalil H, et al. Guidance for conducting systematic scoping reviews. Int J Evid Based Healthc 2015;13:141-6.

30 Shea BJ, Reeves BC, Wells G, et al. AMSTAR 2: a critical appraisal tool for systematic reviews that include randomised or nonrandomised studies of healthcare interventions, or both. BMJ 2017;358:j4008.

31 Tilburgs B, Vernooij-Dassen M, Koopmans R, et al. Barriers and facilitators for GPs in dementia advance care planning: a systematic integrative review. PLoS One 2018;13:e0198535.

32 Dening KH, Jones L, Sampson EL. Advance care planning for people with dementia: a review. Int Psychogeriatr 2011;23:1535-51.

33 Cheong K, Fisher P, Goh J, et al. Advance care planning in people with early cognitive impairment. BMJ Support Palliat Care 2015;5:63-9.
34 Livingston G, Lewis-Holmes E, Pitfield C, et al. Improving the endof-life for people with dementia living in a care home: an intervention study. Int Psychogeriatr 2013;25:1849-58.

35 Livingston G, Pitfield C, Morris J, et al. Care at the end of life for people with dementia living in a care home: a qualitative study of staff experience and attitudes. Int $J$ Geriatr Psychiatry 2012;27:643-50.

36 Robinson L, Dickinson C, Bamford C, et al. A qualitative study: professionals' experiences of advance care planning in dementia and palliative care, 'a good idea in theory but ....'. Palliat Med 2013;27:401-8.

37 Dickinson C, Bamford C, Exley C, et al. Planning for tomorrow whilst living for today: the views of people with dementia and their families on advance care planning. Int Psychogeriatr 2013;25:2011-21.

38 Palan Lopez R, Mitchell SL, Givens JL. Preventing Burdensome transitions of nursing home residents with advanced dementia: it's more than advance directives. J Palliat Med 2017;20:1205-9.

39 Gillett G. Advance decisions in dementia: when the past conflicts with the present. J Med Ethics 2019;45:204-8.

40 Schenell R, Ozanne A, Strang S, et al. Balancing between maintaining and overriding the self: staff experiences of residents' self-determination in the palliative phases. Int J Older People Nurs 2019;14:e12255.

41 Wilson CB, Davies S. Developing relationships in long term care environments: the contribution of staff. J Clin Nurs 2009;18:1746-55.

42 Ajzen I. The theory of planned behaviour: reactions and reflections. Psychol Health 2011;26:1113-27.

43 Leclercq V, Beaudart C, Tirelli E, et al. Psychometric measurements of AMSTAR 2 in a sample of meta-analyses indexed in PsycINFO. J Clin Epidemiol 2020;119:144-5. 